\title{
A HOSPITALIZAÇÃO NO OLHAR DE CRIANÇAS E ADOLESCENTES: SENTIMENTOS E EXPERIÊNCIAS VIVENCIADAS
}

Ilvana Lima Verde Gomes' ${ }^{1}$ Maria Veraci Oliveira Queiroz ${ }^{2}$, Luiza Luana de Araújo Lira Bezerra², Natália Pimentel Gomes Souza ${ }^{4}$

\begin{abstract}
RESUMO: Objetivou-se compreender a hospitalização pelo olhar da criança e do adolescente, observada por meio de seus sentimentose experiências. Estudo qualitativo realizado com 8 participantes internados em uma unidade pediátrica de um hospital público de Fortaleza - Ceará em 2011, os dados foram coletados por meio de entrevistas semiestruturadas e desenho-estória com tema. Da análise dos dados emergiram as categorias: Hospital representado na estrutura física e Significados da hospitalização. A hospitalização é percebida como experiência estressante para crianças e adolescentes por causar agravos emocionais, expressos como tristeza, prisão, saudade de casa, falta dos amigos/irmãos/parentes e impossibilidade de brincar. Os achados permitiram discutir o processo de hospitalização a partir dos pressupostos teóricos da integralidade e da humanização da assistência hospitalar. Conclui-se que há necessidade de (re)pensar o modelo tradicional de assistência a crianças e adolescentes hospitalizados, rumo à humanização do cuidado.
\end{abstract}

PALAVRAS-CHAVE: Criança hospitalizada; Enfermagem pediátrica; Humanização da assistência.

\section{HOSPITALIZATION IN THE VIEW OF CHILDREN AND ADOLESCENTS: FEELINGS AND EXPERIENCES LIVED THROUGH}

ABSTRACT: This qualitative study's aim was to understand hospitalization through the eyes of the child and adolescent, observed through their feelings and experienced. It was undertaken with 8 participants, hospitalized in a pediatric unit in a public hospital in Fortaleza - Ceará in 2011, the data was collected through semi-structured interviews and cartoon-stories on the issue. The following categories emerged from analysis of the data: Hospital represented in physical structure and Meanings of hospitalization. Hospitalization is perceived as a stressful experience for children and adolescents, as it causes emotional harm, expressed as sadness, prison, missing home, lack of friends/siblings/parents, and the impossibility of playing. The findings permitted the discussion of the process of hospitalization based on theoretical assumptions of integrality and humanization of hospital care. It is concluded that there is a need to (re-)think the traditional model of care for hospitalized children and adolescents, in the interests of humanization of care.

KEYWORDS: Hospitalized child; Pediatric nursing; Humanization of care.

\section{LA HOSPITALIZACIÓN EN LA VISIÓN DE NIÑOS Y ADOLESCENTES: SENTIMIENTOS Y EXPERIENCIAS VIVENCIADAS}

RESUMEN: Fue objetivo de este estudiocomprender la hospitalización por la visión del niño y del adolescente, observada por medio de sus sentimientos y experiencias. Este estudio cualitativo fue realizado con 8 participantes internados en una unidad pediátrica de hospital público de Fortaleza-Ceará en 2011, los datos fueron obtenidos por medio de entrevistas semiestructuradas y dibujo-historia con tema. Del análisis de los datos, surgieron las categorías: Hospital representado en la estructura física y Significados de la hospitalización. La hospitalización es percibida como experiencia estresante para niños y adolescentes por causar agravios emocionales, expresos como tristeza, prisión, falta de casa, falta de los amigos/hermanos/familiares y imposibilidad de jugar. Los resultados permitieron discutir el proceso de hospitalización con base en los presupuestos teóricos de la integralidad y de la humanización de la asistencia hospitalar. Se concluye que hay necesidad de (re)pensar el modelo tradicional de asistencia a niños y adolescentes hospitalizados, a fin de llegar a una humanización del cuidado.

PALABRAS CLAVE: Niño hospitalizado; Enfermería pediátrica; Humanización de la asistência.

${ }^{1}$ Enfermeira do Hospital Geral de Fortaleza. Doutora em Saúde Coletiva. Professora do Programa de Pós-Graduação - Mestrado em Saúde Pública e Mestrado Profissional Saúde da Criança e do Adolescente da Universidade Estadual do Ceará - UEC.

${ }^{2}$ Enfermeira. Doutora em Enfermagem. Professora do Curso de Graduação em Enfermagem e do Programa de Pós-Graduação Cuidados Clínicos em Enfermagem e Saúde da UEC.

${ }^{3}$ Enfermeira. Mestranda pelo Programa de Pós-Graduação em Saúde Pública da UEC.

${ }^{4}$ Enfermeira. Mestranda pelo Programa de Pós-Graduação em Cuidados Clínicos em Enfermagem e Saúde da UEC.

Autor correspondente:

Recebido: $15 / 07 / 2012$

Luiza Luana de Araújo Lira Bezerra

Aprovado: 24/11/2012

Universidade Estadual do Ceará

Av. Mister Hull, 2933 - 60356-000 - Fortaleza-CE-Brasil

E-mail: luizaluana@yahoo.com.br 


\section{INTRODUÇÃO}

A hospitalização é um momento difícil na vida de qualquer pessoa. No caso da criança e do adolescente pode se configurar como experiência traumática na medida em que os afasta de sua vida cotidiana e do ambiente familiar e os coloca em um mundo desconhecido, com suas rotinas, equipamentos, pessoas, limitações de movimento, cheiros, procedimentos e dores. Não sem razão, portanto, as internações são carregadas de medos, inseguranças e angústias diversas, tanto para a criança quanto para seus familiares ${ }^{(1)}$.

A experiência da hospitalização, para crianças e adolescentes, pode determinar agravos emocionais, difíceis de serem exteriorizados e traduzidos em palavras. A dificuldade de expressar verbalmente sentimentos e experiências produz conflito interno e o sintoma passa a ser, então, algo difícil de expressar caso não haja manejo adequado da situação por parte da equipe de saúde que o assiste ${ }^{(2)}$.

Os profissionais necessitam não só ter conhecimento e cuidar dos aspectos patológicos da criança e do adolescente, mas percebê-los em seus aspectos emocionais e sociais e se utilizar de técnicas adequadas de comunicação e de relacionamento ${ }^{(3)}$.

Para que haja compreensão das expressões da criança hospitalizada é necessário haver relacionamento sensível e sintonia de sentimentos com a criança $^{(4)}$. O autor exemplifica que o profissional médico, num primeiro momento, co-experimenta a dor e o sofrimento da criança, para perceber num segundo momento o que ela procura na pessoa desse profissional, e que tipo de acolhimento, consolo e conforto pode proporcionar àquela que sofre.

Diante de tais considerações, ressaltamos que entender as experiências vivenciadas por crianças e adolescentes, inclui-se em temática explorada por nós docentes em nosso cotidiano, seja na assistência ou no ensino quando questionamos: quais os sentimentos vivenciados por crianças e adolescentes diante da hospitalização e como melhorar o cuidado a partir de uma comunicação/interação mais efetiva? Tais preocupações têm como horizonte a possibilidade do cuidado integral centrado na criança e na família e apoiados nos pressupostos da humanização.

Observamos em bases de dados e outras literaturas científicas que embora existam muitos trabalhos sobre hospitalização infantil, há carência de trabalhos em que as crianças coloquem sua opinião e sentimentos sobre a hospitalização (frequentemente o responsável é o entrevistado), evidenciando como manifestam seus sentimentos e vivências sobre a hospitalização. Assim, temos a intenção de contribuir nas reflexões acerca do modelo tradicional de intervenção e cuidados a crianças hospitalizadas, (re)pensar modelos alternativos que favoreçam maior participação dos atores e contribuir na construção de sua autonomia.

O estudo objetivou compreender a hospitalização pelo olhar da criança e do adolescente observado por meio de seus sentimentos e experiências.

\section{MÉTODO}

Trata-se de uma pesquisa exploratória, ancorada em abordagem qualitativa. O campo da pesquisa foi a unidade pediátrica de um hospital geral localizado na cidade de Fortaleza/Ceará, composta por 10 enfermarias comuns e uma de isolamento, totalizando 38 leitos de diversas especialidades: pediatria clínica, ortopedia, otorrinolaringologia e cirurgias pediátrica e plástica. O hospital é o maior da rede pública do Ceará, terciário, referência para o Estado e outras regiões do Brasil.

A pesquisa de campo foi iniciada após aprovação do Comitê de Ética em Pesquisa do hospital sob protocolo número 071007/10. Cumprindo os preceitos éticos da pesquisa com seres humanos, todas as crianças e seus responsáveis legais tiveram ciência dos objetivos da pesquisa e a forma de participação, ressaltando-se a preservação dos aspectos éticos contidos no Termo de Consentimento Livre e Esclarecido. Assim, os participantes (crianças e adolescentes) e o respectivo responsável deram anuência formal.

Como critério de inclusão os participantes da pesquisa deveriam estar hospitalizados há mais de cinco dias, ou seja, um tempo mínimo para que os mesmos pudessem tomar ciência do que seja o hospital; ser maior de seis anos e menor de 18 anos, pela necessidade do participante desenhar e falar do seu desenho; independente do número de internações; e estar internado com uma patologia que não o impedisse de participar do estudo. A coleta de dados foi concluída com 8 participantes, quanto observou-se a repetição das respostas e observando-se o critério de saturação teórica ${ }^{(5)}$. Os participantes estavam na faixa etária de 7 a 15 anos, sendo que a maior parte, ou seja, 7 vivenciavam pela primeira vez a internação; cinco eram do sexo masculino e três do sexo feminino. Quatro procediam do interior do Estado e quatro moravam na capital. Para identificação e preservação do anonimato dos partici- 
pantes usou-se codinomes criados aleatoriamente, sem relação com sua identidade.

A coleta das informações se deu nos meses de julho a agosto de 2011, aproveitando os momentos em que as crianças/adolescentes não estavam em uso de medicação ou passando por procedimentos, como fisioterapia, exames de imagem, entre outros. Como técnica de coleta de dados utilizou-se a entrevista semiestruturada, gravada, associada à técnica do Desenho-Estória com Tema. Cada criança/adolescente foi abordado individualmente acompanhado de seu responsável. Expressões não verbais e outras situações foram registradas no diário de campo.

Desenho-Estória com Tema é o desenho como representação gráfica de pensamentos e sentimentos, uma das formas de comunicação humana mais primitiva; este é usado amplamente como método de coleta de dados em pesquisas qualitativas, principalmente quando os participantes do estudo são crianças ${ }^{(6-7)}$.

Para aproximar-se das situações vividas contamos uma estória para cada criança adolescente sobre um macaquinho que brincava na floresta com seus amigos, quando um dia ficou doente e foi levado ao hospital pelos seus pais. A partir daí, convidamos individualmente o participante, que se mostrava atento e cooperativo para desenhar o que pensava sobre o que o macaquinho achava do hospital, e num segundo desenho como ele se sentia no hospital. Após cada desenho, ele relatavam o que significava cada desenho. Para esta atividade fornecemos folhas de papel ofício e lápis de cor. Um adolescente preferiu escrever em vez de fazer o segundo desenho, e uma criança em um só desenho representou seus sentimentos. Cada participante teve o tempo que necessitou para fazer seus desenhos e relatar sua estória. Tivemos como apoio a sala que nos foi reservada para a pesquisa, porém, em dois momentos entrevistamos os participantes na própria enfermaria por dificuldades para a sua locomoção.

A análise das informações teve início com a leitura exaustiva das entrevistas, identificação e codificação de temas relevantes, de acordo com os objetivos do estudo, procedendo com o recorte das falas, agrupando-as por semelhanças e procurando confrontar os vários discursos. Desta organização emergiram duas categorias: Hospital representado na estrutura física e Significados da hospitalização para crianças e adolescentes. Seguindo essa etapa os resultados foram interpretados à luz do referencial teórico pertinente, acrescidos das experiências dos pesquisadores.

\section{RESULTADOS}

\section{Hospital representado na estrutura física}

O primeiro desenho solicitado foi sobre o que era o hospital para o macaquinho; 7 desenharam o hospital na sua estrutura física, somente um desenhou a enfermaria. Ao serem instigadas a descrever o significado do desenho relataram suas percepções, alternando entre a realidade e o desejo de como deveria ser.

Ohospital tem janelas para ver o mar e para o vento. (Dan)

Tia, é uma área de lazer para as crianças, tem muita diversão no hospital, tem uma sala de brinquedo. Você brinca de manhã, de tarde e de noite [...]. (Thomas)

\section{[...] aqui [na enfermaria] deveria ter uma TV. (Jorge)}

Local bonito. (Lulu; Pablo; Gaspard)

\section{Significados da hospitalização}

O desenho produzido traz, em sua essência, significados da internação hospitalar. Foram respostas elaboradas pontualmente, mas que representam o imaginário e são carregadas de sentimentos do aspecto negativo da hospitalização, tais como: tristeza, prisão, saudade de casa, falta dos amigos/irmãos/parentes e de brincar, medo, estranheza, solidão, insegurança.

A primeira criança preferiu escrever e expressou a sensação de prisão por não poder sair e brincar, mesmo assim identificou o hospital como sua segunda casa (Figura 1).

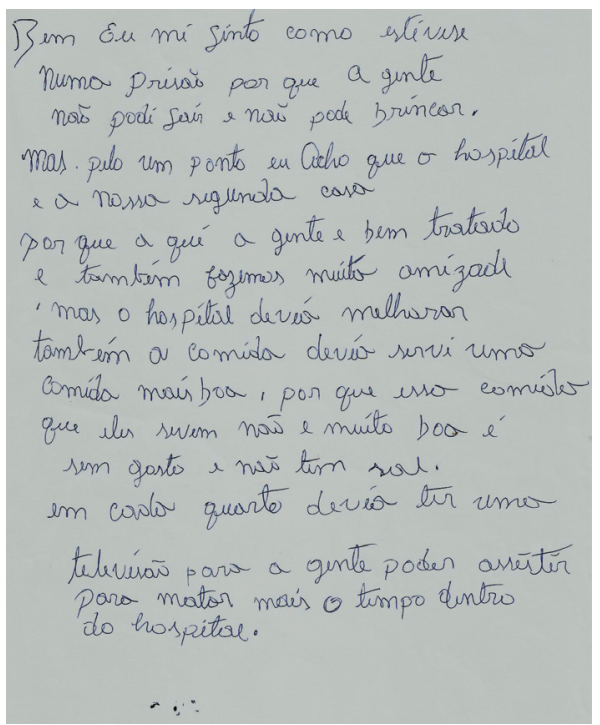

Figura 1 - Desenho de Jorge. Fortaleza, 2011 
A condição de sentir-se na prisão emergiu em outras falas e desenhos (Figura2).

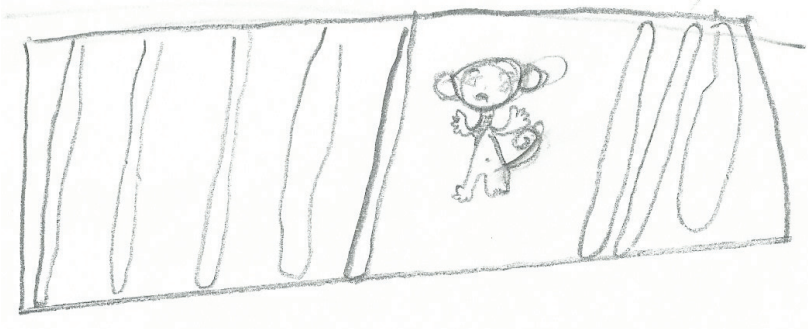

Figura 2 - Desenho de Lulu Fortaleza, 2011

Ao questionarmos por que esse macaquinho se sentia na prisão, as respostas foram:

A gente não pode sair, não pode brincar. (Jorge)

O macaquinho só sai dai quando o médico dá alta. (Lulu)

Em seus desenhos o macaquinho estava numa cela, ilustrando uma prisão. Isso causou um forte impacto quando se realizava as entrevistas, tal fato levou as pesquisadoras a conversar com os profissionais da unidade sobre o sentimento expresso. O sentimento de estar numa prisão foi referido porque, além de não poder sair da unidade, não podia brincar ou brincava pouco. Isso levava a outros sentimentos, o de tristeza, saudade de casa e dos amigos e solidão:

Triste porque ele quer brincar, quer voltar para casa, para perto dos amigos. (Thomas)

[O macaquinho sente falta de quê?] De casa. [O que precisa para o macaquinho ficar feliz?] Brincar. (Lulu)

Me sinto sozinho, eu sinto falta de brincar. [Sua mãe está perto de você!] É, ela está aqui, mas [...] eu sinto falta dos meus amigos. (Dan)

\section{DISCUSSÃO}

O hospital em estudo vem passando por um processo de reforma e ampliação. Entretanto, as instalações e a estrutura física da unidade de pediatria ainda não se adequam à proposta de humanização da assistência à criança e ao adolescente hospitalizados. A pediatria foi entregue há cerca de três anos, nela foi construída uma sala para a terapia ocupacional que fica vizinha ao refeitório da unidade. Há uma televisão no refeitório e a sala da terapia ocupacional só é usada quando as duas terapeutas estão no setor, isso não ocorre todos os dias.

Dessa forma, percebe-se que a preocupação com o espaço físico e com o impacto da hospitalização para crianças e adolescentes são pontos que merecem destaque e devem ser reconhecidos pelos profissionais e gestores das instituições de saúde. Os participantes expressaram o hospital por meio de desenhos coloridos, o que deve ser observado ao planejar uma unidade de internação. As paredes dos hospitais e outras instituições de saúde que prestam assistência a crianças e adolescentes devem ser coloridas, receber pinturas de personagens infantis e brincadeiras. O objetivo vai além de enfeitar as paredes, mas de dar às crianças e aos adolescentes a oportunidade de conhecer e desmistificar os procedimentos médicos por meio da participação interativa e da brincadeira no processo terapêutico.

O hospital ao longo dos séculos vem sofrendo modificações na sua arquitetura e ambiência. Gradativamente, deixou de ser uma simples figura arquitetônica, um lugar onde se internavam doentes, loucos, devassos, prostitutas, com estigmas da miséria, de morredouro. Passou, a ser um instrumento de cura, um campo documental, ou seja, de registro e, também, um lugar de formação médica ${ }^{(8-9)}$.

Essas mudanças, no decorrer do tempo, trouxeram reflexões também acerca da humanização da assistência hospitalar. O Programa Nacional de Humanização da Assistência Hospitalar foi transformado, em 2004, em Política Nacional de Humanização e propõe investir no tratamento dado ao espaço físico, ou seja, à ambiência. $\mathrm{O}$ conceito de ambiência pontua três concepções: o espaço que visa ao conforto focado na privacidade e individualidade dos sujeitos envolvidos; o espaço que possibilita a produção de subjetividades e o espaço usado como ferramenta facilitadora do processo de trabalho ${ }^{(10)}$.

Um estudo de cunho exploratório, que abordou o discurso do Ministério da Saúde sobre a humanização da assistência, identificou três eixos discursivos relacionados aos significados associados à humanização. $\mathrm{O}$ terceiro eixo discursivo traz a ideia de humanização como melhoria da infraestrutura dos hospitais, das instalações físicas, renovação de equipamentos, entre outros ${ }^{(11)}$. Espera-se que esse processo de humanização se traduza em melhor qualidade de atendimento à saúde do usuário e em melhores condições de trabalho para os profissionais. Nesta perspectiva, ainda se percebe um distanciamento da nossa realidade e as prerrogativas oficiais.

Outra pesquisa mostra a grande lacuna para que os 
hospitais tenham a ambiência adequada para acolher seus usuários, pois, de modo geral a estrutura física hospitalar é planejada para ser funcional para os trabalhadores. Assim, os responsáveis no planejamento e execução de projetos de ambientes hospitalares esquecem de deixá-lo aconchegante para receber o doente, principalmente a criança doente ${ }^{(12)}$.

Os hospitais deveriam ter decorações mais aconchegantes, um ambiente caseiro, com roupas e camas comuns, objetos pessoais; cores alegres nas enfermarias. A criança deve dispor de um lugar, próximo da sua cama ou berço, para colocar seus desenhos, fotos, recados de amigos ou da família; que haja desenhos e brinquedos visíveis nas enfermarias. O lúdico precisa fazer parte do seu cotidiano hospitalar, com materiais e profissionais adequados para o seu desenvolvimento. Também é importante uma acomodação confortável para seu acompanhante, que poderá permanecer muito tempo no hospital ${ }^{(12)}$.

O sofrimento físico decorrente da doença que atinge a criança internada é acrescido de sofrimento psíquico, uma condição inevitável, caracterizado pelo processo de hospitalização. Este sofrimento traz uma mensagem social, física e psíquica. Compreender o jeito como a criança lê a realidade e a expressa é o caminho para acessarmos sua subjetividade ${ }^{(13)}$.

Ainda, podemos afirmar que a violência simbólica, do não reconhecimento das subjetividades do usuário, perpassa a própria história das instituições hospitalares. O hospital moderno teve como marca histórica de sua constituição organizacional impor aos pacientes o isolamento, a despersonalização e a submissão disciplinar de seus corpos (e subjetividades) a procedimentos e decisões que sequer compreendem ${ }^{(11)}$.

As crianças/adolescentes narram a falta do brincar, ou a oportunidade do brincar pouco. O brincar faz parte da infância, constitui uma ferramenta necessária para os processos de socialização, comunicação, habilidades, e amplia as possibilidades de desenvolvimento global da criança. O brincar, para uma criança hospitalizada, pode ser um espaço privilegiado para fazê-la falar sobre essa singularidade do processo de adoecimento e hospitalização ${ }^{(14-15)}$. A atividade lúdica, promove fatores significativos para o desenvolvimento psicomotor, cognitivo, social e afetivo da criança, proporcionando um tratamento humanizado ${ }^{(16)}$.

De acordo com o item 9 da Resolução 41/95, que trata dos direitos da criança hospitalizada, essa tem direito a desfrutar de alguma forma de recreação enquanto estiver internada. O Estatuto da Criança e do
Adolescente no Art. 16, refere que o direito à liberdade compreende vários aspectos, entre eles o de brincar, praticar esportes e divertir-e ${ }^{(17)}$. Além disto, a Lei 11.104 de 21/03/2005 dispõe sobre a obrigatoriedade de instalações de brinquedotecas em todas as unidades de saúde, públicas ou privadas, que ofereçam atendimento pediátrico em regime de internação ${ }^{(18)}$.

Portanto, os hospitais que recebem crianças devem dispor de um local e de profissionais capacitados para promover o brincar, que significa manter atividades recreativas e lúdicas, que despertem sensações de alegria. Tal abordagem precisa fazer parte da rotina dos atendimentos como intervenção terapêutica na atenção a crianças hospitalizadas, de forma sistemática e contínua, e não se restringir a ações pontuais e desarticuladas. Ter um profissional específico para tal função, contudo, não significa dizer que os outros profissionais de saúde irão renegar esse cuidado, esse momento. O brincar faz parte do cuidado e proporciona uma abordagem humanizada.

Nos desenhos das crianças/adolescentes deste estudo foram demonstrados sentimentos de solidão e saudade dos amigos e parentes. Assim, podemos relacionar com momentos vividos na unidade hospitalar em estudo, onde a visita é diária, das 16 às 17 horas, para adultos. Mesmo a criança/adolescente permanecendo acompanhado pelo seu responsável durante toda a sua internação, direito este resguardo no Estatuto da Criança e do Adolescente ${ }^{(19)}$ ela sente falta dos outros familiares e amigos, que geralmente, não podem visitá-los durante a semana em horário estabelecido pelo hospital do estudo. Fato este já foi discutido em eventos dentro do hospital, sendo considerada a visita aberta uma solução, pois permite que o horário de visita seja expandido. Atualmente, precisa-se do consentimento da Assistente Social ou da Enfermeira para que um familiar entre fora do horário; se o visitante for uma criança é avaliado se esta tem condições de realizar a visita, porém não é uma regra essa conduta. Seria interessante ter, como rotina, um dia de visita de menores, já que a unidade possui um espaço livre antes das enfermarias, diminuindo assim, o risco de contaminação das crianças internadas e para as que visitam.

\section{CONSIDERAÇÕES FINAIS}

O estudo traz o significado da hospitalização e sentimentos expressos por crianças e adolescentes em suas vivências no cotidiano hospitalar. Informações apreendidas por meio de desenhos e complementados por depoimentos que, de certa forma, oportunizaram a maior liberdade nas manifestações.

O hospital é representado na estrutura física entre 
a realidade e o desejo de como deveria ser. Também é entendido como lugar de cura e cuidados e fica implícito que esses cuidados trazem melhoria de saúde para os usuários que se submetem à condição de hospitalização. Revela-se um aspecto ambíguo, pois embora seja considerado um local para ficar bom, os participantes evidenciam sentimentos de tristeza, medo, prisão, saudade pela falta dos amigos/irmãos/parentes e a falta de brincar parece aumentar a solidão e a insegurança que vivenciam nesta experiência.

Crianças e adolescentes, de forma sutil, mostram a realidade de uma unidade pediátrica de um hospital terciário, que embora tenha passado por grandes reformas na estrutura física, ainda apresenta carências. Neste sentido, é preciso um cuidado humanizado e atento ao olhar dessas crianças e adolescentes para que estes expressem suas muitas necessidades, que vão além do aspecto biológico. Outras dimensões psicossociais estão diretamente implicadas na recuperação da saúde e no crescimento e desenvolvimento desses usuários, assim, estes aspectos expressos, necessitam serem reconhecidos e compreendidos pelos profissionais. Contudo, sua necessidade de ter demandas e expectativas compreendidas não pode ficar no invisível pelo enfermeiro e demais membros da equipe de saúde, com o intuito de propiciar contribuição para a melhoria da qualidade da atenção prestada.

\section{REFERÊNCIAS}

1. Gomes ILV, Caetano R, Jorge MSB. Conhecimento dos profissionais de saúde sobre os direitos da criança hospitaliza: um estudo exploratório. Ciênc. saúde colet. [Internet] 2010;15(2) [acesso em 5 abr 2011]. Disponível: $<$ http://www.scielosp.org/scielo.php?script=sci arttext\&pid $=$ S1413-81232010000200023\&lng=en\&n $\mathrm{rm}=$ iso $>$. ISSN 1413-8123. http://dx.doi.org/10.1590/ S1413-81232010000200023.: 463-70.

2. Barus-Michel, J. Sofrimento e perda de sentido: condições psicossociais e clínicas. PSIC. 2003;4(1):54-71.

3. Almeida FM, Sabatés AL. Enfermagem pediátrica: a criança, o adolescente e sua família no hospital. São Paulo: Manole; 2008.

4. Oliveira H. Ouvindo a criança sobre a enfermidade e a hospitalização. In: Ceccim RB, Carvalho PRA. Criança hospitalizada: atenção integral como escuta à vida. Porto Alegre: Editora da Universidade/UFRGS; 1997. p. $42-55$.

5. Fontanella BJB, Ricas J, Turato ER. Amostragem por saturação em pesquisas qualitativas em saúde: contribuições teóricas. Cad. Saúde Pública. [Internet] 2008;24(1) [acesso em 5 abr 2011]. Disponível: http:// www.scielosp.org/pdf/csp/v24n1/02.pdf

6. Goldberg LG, Yunes MAM; Freitas JVO. Desenho infantil na ótica da ecologia do desenvolvimento humano. Psicol. estud. 2005;10(1):97-106.

7. Trinca TW. Formas de investigação clínica em psicologia: procedimento de desenhos-estórias: procedimentos de desenhos de família com estórias. São Paulo: Vetor; 1997.

8. Foucault M. O nascimento da clínica. $5^{\mathrm{a}}$ ed. Rio de Janeiro: Forense Universitária; 2003.

9. Foucault M. Vigiar e punir. $28^{\mathrm{a}}$ ed. Petrópolis: Vozes; 2004.

10. Ministério da Saúde (BR). O SUS de A a Z : garantindo saúde nos municípios. $3^{\mathrm{a}}$ ed. Brasília: Ministério da Saúde; 2009. [acesso em 05 abr de 2011]. Disponível: http://portal.saude.gov.br/portal/arquivos/ pdf/sus_3edicao_completo.pdf.

11. Deslandes SF. Análise do discurso oficial sobre a humanização da assistência hospitalar. Ciênc. saúde colet. [Internet] 2004;9(1) [acesso em 5 abr 2011]. Disponível: http://www.scielo.br/scielo.php?script=sci arttext\&pid=S1413-81232004000100002\&lng=en\& nrm=iso ISSN 1413-8123. http://dx.doi.org/10.1590/ S1413-81232004000100002.

12. Gomes ILV. A criança hospitalizada, seus direitos e as relações interpessoais no cuidado e tratamento: caminhos e descaminhos [tese]. Rio do Janeiro (RJ): Universidade do Estado do Rio de Janeiro; 2007.

13. Souza SV, Camargo D, Bulgacova YLM. Expressão da emoção por meio do desenho de uma criança hospitalizada. Psicol. estud. 2003;8(1):101-9.

14. Valladares ACA. Arteterapia com crianças hospitalizadas [dissertação]. Ribeirão Preto (SP): Universidade de São Paulo; 2003.

15. Mitre RMA. Brincando para viver: um estudo sobre a relação entre a criança gravemente adoecida e hospitalizada e o brincar [dissertação]. Rio do Janeiro (RJ): Fundação Oswaldo Cruz; 2000.

16. Frota, MA, Gurgel AA, Pinheiro MCD, Martins MC, Tavares TANR. O lúdico como instrumento facilitador na humanização do cuidado de crianças hospitalizadas. 
Cogitare enferm. [Internet] 2007;12(1) [acesso em 5 abr 2011]. Disponível: http://ojs.c3sl.ufpr.br/ojs2/index.php/ cogitare/article/view/8270/5781

17. Brasil. Conselho Nacional de Defesa dos Direitos da Criança e Adolescente. Resolução n. 41, de 13 de outubro de 1995. Dispõe sobre os direitos da criança hospitalizada. Diário Oficial da Republica Federativa do Brasil, Brasília, 17 out 1995. Sessão 1.

18. Brasil. Lei n. 11.104, de 21 de março de 2005. Dispõe sobre a obrigatoriedade de instalação de brinquedotecas nas unidades de saúde que ofereçam atendimento pediátrico em regime de internação. Diário Oficial da República Federativa do Brasil [Internet] 22 mar 2005 [acesso em 17 out 2012]. Disponível: http:// www. planalto.gov.br/ccivil_03/_Ato2004-2006/2005/Lei/ L11104.htm

19. Ministério da Justiça (BR). Lei n. 8.069, de 13 de julho de 1990. Dispõe sobre o Estatuto da Criança e do Adolescente e dá outras providências, [Internet] 1990 [acesso em 19 jun 2011]. Disponível: http://www. planalto.gov.br/ccivil_03/Leis/L8069.htm\#art17 